\title{
Nitrogen Containing Linear Poly(phenylene) Derivatives for Photo- catalytic Hydrogen Evolution from Water
}

\author{
Reiner Sebastian Sprick, ${ }^{*}{ }^{\dagger} \odot$ Liam Wilbraham, ${ }^{\ddagger}$ Yang Bai, ${ }^{\dagger}$ P Pierre Guiglion, ${ }^{\ddagger}$ Adriano Monti, ${ }^{\ddagger}$ \\ Rob Clowes, ${ }^{\dagger}$ Andrew I. Cooper, ${ }^{\dagger}{ }^{\circ}$ and Martijn A. Zwijnenburg, ${ }^{*},+\circ$ \\ ${ }^{\dagger}$ Department of Chemistry and Material Innovation Factory, University of Liverpool, Crown Street, Liverpool, L69 7ZD, United \\ Kingdom \\ ${ }^{\ddagger}$ Department of Chemistry, University College London, 20 Gordon Street, London, WC1H 0AJ, United Kingdom
}

\section{Supporting Information}

ABSTRACT: Here we study how the introduction of nitrogen into poly $(p$ phenylene) type materials affects their ability to act as hydrogen evolution photocatalysts. Direct photocatalytic water splitting is an attractive strategy for clean energy production, but understanding which material properties are important, how they interplay, and how they can be influenced through doping remains a significant challenge, especially for polymers. Using a combined experimental and computational approach, we demonstrate that introducing nitrogen in conjugated polymers results in either materials that absorb significantly more visible light but worse predicted driving force for water/sacrificial electron donor oxidation, or materials with an improved driving force that absorb relatively

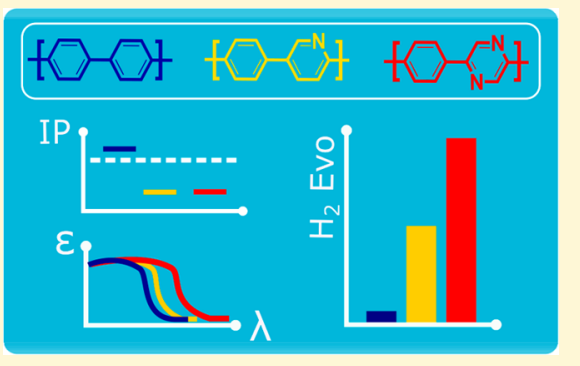
less visible light. The latter materials are found to be much more active and the former much less. The trade-off between properties highlights that the optimization of a single property in isolation is a poor strategy for improving the overall activity of materials.

\section{INTRODUCTION}

Most current primary energy sources release greenhouse gas and air pollutants. Hydrogen as an energy carrier has been identified as a "green" alternative ${ }^{1}$ because it can be used to generate energy without releasing $\mathrm{CO}_{2}$ or other pollutants in fuel cells ${ }^{2}$ and hydrogen-fueled combustion engines. ${ }^{3}$ It can also reduce emissions in hybrid systems such as hydrogenenriched compressed natural gas internal combustion engines. ${ }^{4}$ While this reduces the carbon footprint at the point of use, production still remains an issue because most hydrogen is currently obtained using either methane steam reforming or the water-gas shift reaction. Hydrogen generation from renewable energy sources is a promising and attractive way to minimize the carbon footprint at the point of production. Photocatalytic water splitting into hydrogen and oxygen is of interest as it opens a potential pathway to clean hydrogen production using only water (including potentially seawater) and solar light, both of which are almost inexhaustible.

Traditionally, the field of suspension photocatalysis for water splitting has been dominated by metal oxides, chalcogenides, and inorganic nitrides. ${ }^{5,6}$ Studies of organic rather than inorganic photocatalysts go back to at least 1985, with early work on oligo- and poly ( $p$-phenylene $) \mathrm{s}$ for hydrogen evolution in the presence of a sacrificial electron donor (SED). ${ }^{7-10}$ However, the area only gained serious traction after the pioneering 2009 work by Wang et al. ${ }^{11}$ who demonstrated that carbon nitride materials could reduce protons to hydrogen and oxidize water to oxygen under illumination in the presence of a SED and sacrificial electron acceptor (SEA), respectively. This resulted in a large number of follow-up studies on carbon nitride, ${ }^{11,12,21-29,13-20}$ with various strategies such as the use of heterojunctions, ${ }^{20,30,31}$ or other donor-acceptor like systems, ${ }^{32}$ copolymerization, ${ }^{18,33,34}$ doping with other elements, ${ }^{35-38}$ control of end-groups, ${ }^{26}$ and structuring ${ }^{16,39-41}$ to improve the photocatalytic activity. Other organic photocatalysts have also been explored, including conjugated microporous polymers, ${ }^{42-47}$ linear conjugated polymers, ${ }^{48-53}$ triazine-type materials, ${ }^{54-59}$ and covalent organic frameworks (COFs). ${ }^{6-62}$ The activity of these materials has also been enhanced by similar approaches such as copolymerization with a wide range of monomers ${ }^{48-53}$ and reducing the size of

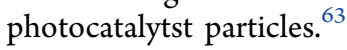

In all cases, the polymers absorb the light, generating the charge carriers required to drive the reduction and oxidation reactions. Frequently, the polymers are assisted by metal cocatalyst that (further) reduce the barriers for the chemical reaction steps. In many cases it is unclear whether the polymer acts as a light absorber, as a catalyst, or as both, but it is clear that no hydrogen is evolved in the dark or in the absence of the polymer.

The presence of heteroatoms and especially nitrogen atoms in several of the more active organic photocatalysts is a recurring theme. Besides carbon nitrides, examples include oligomers of pyridine, ${ }^{64}$ homopolymers of pyridine ${ }^{65}$ and

Received: June 13, 2018

Revised: July 23, 2018

Published: July 24, 2018 
bipyridine, ${ }^{66}$ conjugated microporous co-polymers based on nitrogen containing monomers, ${ }^{44}$ azine-linked triazine COFs, ${ }^{60}$ and covalent triazine-based frameworks (CTFs). ${ }^{54,55,57}$ The photocatalytic activity of such materials has been proposed, based on calculations, to be the result of better driving forces for the oxidation of water/SEDs, ${ }^{67,68}$ as well as greater planarity of structures resulting in improved conjugation and lower optical gaps. ${ }^{69,70}$

What has been lacking, however, is an integrated experimental and computational study where the effect of the incorporation of nitrogen and other heteroatoms on the activity of well-defined photocatalysts is explored systematically. We address this gap in our understanding here by preparing, characterizing, and testing as photocatalysts under sacrificial conditions a series of linear homo- and copolymers that contain one or two nitrogen atoms per formal repeat unit, as well as poly(thiophene $)^{53}$ and poly( $p$-phenylene $)^{7,52}$ as examples of polymers containing an alternative heteroatom and no heteroatoms. We probe the effect of the heteroatom, the heteroatom content, and the chemical environment of the heteroatom on the photocatalytic activity and attempt to deconvolute the role of changes in the optical gap and thermodynamic driving force, among other factors.

\section{EXPERIMENTAL SECTION}

Reactions were carried out under nitrogen atmosphere using standard Schlenk techniques. CHN analysis was performed on a Thermo EA1112 Flash CHNS-O analyzer using standard microanalytical procedures. UV-visible absorption spectra of the polymers were recorded on a Shimadzu UV-2550 UV-vis spectrometer as powders in the solid state. The fluorescence spectra of the polymer powders were measured with a Shimadzu RF-5301PC fluorescence spectrometer at room temperature. Static contact angle measurements with the sessile drop method were recorded and analyzed at room temperature on a Krüss DSA100 instrument measured in at least three different locations with water. TCSPC experiments were performed on an Edinburgh Instruments LS980-D2S2-STM spectrometer equipped with picosecond pulsed LED excitation sources and a R928 detector, with a stop count rate below 4\%. An EPL-375 diode ( $\lambda$ $=370.5 \mathrm{~nm}$, instrument response $100 \mathrm{ps}$ fwhm) with a $450 \mathrm{~nm}$ high pass filter for emission detection was used. Suspensions were prepared by ultrasonicating the polymer in water. The instrument response was measured with colloidal silica (LUDOX HS-40, Sigma-Aldrich) at the excitation wavelength without filter, and decay times were fitted in Fluoracle software.

Synthesis. General Procedure Suzuki-Miyaura-Type Polycondensation. A flask was charged with the monomers, $\mathrm{N}, \mathrm{N}$ dimethylformamide, an aqueous solution of $\mathrm{K}_{2} \mathrm{CO}_{3}(2.0 \mathrm{M})$, and $\left[\mathrm{Pd}\left(\mathrm{PPh}_{3}\right)_{4}\right]$. The mixture was degassed by bubbling with $\mathrm{N}_{2}$ for 30 min and heated to $150{ }^{\circ} \mathrm{C}$ for 2 days. The mixture was cooled to room temperature and poured into water. The precipitate was collected by filtration and washed with $\mathrm{H}_{2} \mathrm{O}$ and methanol. Further purification of the polymers was carried out by Soxhlet extraction with chloroform to remove any low-molecular weight byproducts, and the product was dried under reduced pressure. Note: The yields were calculated ignoring the presence of end-groups whose nature is unclear.

Synthesis of P23. 4-Bromo- $N$-(4-bromophenyl)- $N$-phenylaniline (403 mg, $1.0 \mathrm{mmol}$ ), benzene-1,4-diboronic acid (166 mg, $1.0 \mathrm{mmol}$ ), $\mathrm{K}_{2} \mathrm{CO}_{3}(3 \mathrm{~mL}, 2.0 \mathrm{M}), N, N$-dimethylformamide $(15 \mathrm{~mL})$, and $\left[\mathrm{Pd}\left(\mathrm{PPh}_{3}\right)_{4}\right](15 \mathrm{mg})$ were used in this polymerization. After workup and Soxhlet extraction with chloroform, the product was obtained as a yellow powder $(219 \mathrm{mg}, 69 \%)$. Anal. Calcd for $\left(\mathrm{C}_{24} \mathrm{H}_{17} \mathrm{~N}\right)_{n}$ : C, 90.25; H, 5.36; N, 4.12\%; Found C, 82.33; H, 5.00; N, 4.12\%.

Synthesis of P24. 2,5-Dibromopyridine (474 mg, $2.0 \mathrm{mmol}$ ), benzene-1,4-diboronic acid $(332 \mathrm{mg}, 2.0 \mathrm{mmol}), \mathrm{K}_{2} \mathrm{CO}_{3}(8 \mathrm{~mL}, 2.0$ $\mathrm{M}), \mathrm{N}, \mathrm{N}$-dimethylformamide $(40 \mathrm{~mL})$, and $\left[\mathrm{Pd}\left(\mathrm{PPh}_{3}\right)_{4}\right](40 \mathrm{mg})$ were used in this polymerization. After workup and Soxhlet extraction with chloroform, the product was obtained as a dark green powder (268 mg, 87\%). Anal. Calcd for $\left(\mathrm{C}_{11} \mathrm{H}_{7} \mathrm{~N}\right)_{n}: \mathrm{C}, 86.25 ; \mathrm{H}, 4.61 ; \mathrm{N}$, 9.14\%; Found C, 70.33; H, 4.14; N, 7.19\%.

Synthesis of P25. 3,5-Dibromopyridine (474 mg, $2.0 \mathrm{mmol}$ ), benzene-1,4-diboronic acid $(332 \mathrm{mg}, 2.0 \mathrm{mmol}), \mathrm{K}_{2} \mathrm{CO}_{3}(8 \mathrm{~mL}, 2.0$ $\mathrm{M}), \mathrm{N}, \mathrm{N}$-dimethylformamide $(40 \mathrm{~mL})$, and $\left[\mathrm{Pd}\left(\mathrm{PPh}_{3}\right)_{4}\right](40 \mathrm{mg})$ were used in this polymerization. After workup and Soxhlet extraction with chloroform, the product was obtained as a gray powder $(288 \mathrm{mg}$, 93\%). Anal. Calcd for $\left(\mathrm{C}_{11} \mathrm{H}_{7} \mathrm{~N}\right)_{n}: \mathrm{C}, 86.25 ; \mathrm{H}, 4.61 ; \mathrm{N}, 9.14 \%$; Found $\mathrm{C}, 67.59 ; \mathrm{H}, 3.89$; N, 7.13\%.

Synthesis of P26. 2,6-Dibromopyridine (474 mg, $2.0 \mathrm{mmol}$ ), benzene-1,4-diboronic acid $(332 \mathrm{mg}, 2.0 \mathrm{mmol}), \mathrm{K}_{2} \mathrm{CO}_{3}(8 \mathrm{~mL}, 2.0$ $\mathrm{M}), \mathrm{N}, \mathrm{N}$-dimethylformamide $(40 \mathrm{~mL})$, and $\left[\mathrm{Pd}\left(\mathrm{PPh}_{3}\right)_{4}\right](40 \mathrm{mg})$ were used in this. After workup and Soxhlet extraction with chloroform, the product was obtained as a gray powder $(233 \mathrm{mg}$, 76\%). Anal. Calcd for $\left(\mathrm{C}_{11} \mathrm{H}_{7} \mathrm{~N}\right)_{n}: \mathrm{C}, 86.25 ; \mathrm{H}, 4.61 ; \mathrm{N}, 9.14 \%$; Found C, 67.89; H, 3.91; N, 7.20\%.

Synthesis of P27. 2,5-Dibromopyridin-1-ium-1-olate (506 mg, 2.0 $\mathrm{mmol})$, benzene-1,4-diboronic acid $(332 \mathrm{mg}, 2.0 \mathrm{mmol}), \mathrm{K}_{2} \mathrm{CO}_{3}(3$ $\mathrm{mL}, 2.0 \mathrm{M}), \mathrm{N}, \mathrm{N}$-dimethylformamide $(40 \mathrm{~mL})$, and $\left[\mathrm{Pd}\left(\mathrm{PPh}_{3}\right)_{4}\right](15$ $\mathrm{mg}$ ) were used in this polymerization. After workup and Soxhlet extraction with chloroform, the product was obtained as a dark green powder $(239 \mathrm{mg}, 71 \%)$. Anal. Calcd for $\left(\mathrm{C}_{11} \mathrm{H}_{7} \mathrm{NO}\right)_{n}$ : C, 78.09; $\mathrm{H}$, 4.17; N, 8.28\%; C, 63.60; H, 3.69; N, 7.43\%.

Synthesis of P28. 2,5-Dibromopyrazine (476 mg, $2.0 \mathrm{mmol}$ ), benzene-1,4-diboronic acid $(332 \mathrm{mg}, 2.0 \mathrm{mmol}), \mathrm{K}_{2} \mathrm{CO}_{3}(8 \mathrm{~mL}, 2.0$ $\mathrm{M}), \mathrm{N}, \mathrm{N}$-dimethylformamide $(40 \mathrm{~mL})$, and $\left[\mathrm{Pd}\left(\mathrm{PPh}_{3}\right)_{4}\right](40 \mathrm{mg})$ were used in this polymerization. After workup and Soxhlet extraction with chloroform, the product was obtained as a dark green powder $(318 \mathrm{mg}, 99 \%)$. Anal. Calcd for $\left(\mathrm{C}_{10} \mathrm{H}_{6} \mathrm{~N}_{2}\right)_{n}: \mathrm{C}, 77.91 ; \mathrm{H}, 3.92 ; \mathrm{N}$, 18.17\%; Found C, 64.38; H, 3.62; N, 14.69\%.

Synthesis of P29. 2,5-Dibromopyrrimidine $(476 \mathrm{mg}, 2.0 \mathrm{mmol})$, benzene-1,4-diboronic acid $(332 \mathrm{mg}, 2.0 \mathrm{mmol}), \mathrm{K}_{2} \mathrm{CO}_{3}(8 \mathrm{~mL}, 2.0$ $\mathrm{M}), \mathrm{N}, \mathrm{N}$-dimethylformamide $(40 \mathrm{~mL})$, and $\left[\mathrm{Pd}\left(\mathrm{PPh}_{3}\right)_{4}\right](40 \mathrm{mg})$ were used in this polymerization. After workup and Soxhlet extraction with chloroform, the product was obtained as a dark gray powder (251 mg, 81\%). Anal. Calcd for $\left(\mathrm{C}_{10} \mathrm{H}_{6} \mathrm{~N}_{2}\right)_{n}: \mathrm{C}, 77.91 ; \mathrm{H}, 3.92 ; \mathrm{N}$, 18.17\%; Found C, 62.27; H, 3.67; N, 13.64\%.

Synthesis of P30. 5,5'-Dibromo-2,2'-bipyridine ( $1.26 \mathrm{~g}, 4.0 \mathrm{mmol})$, benzene-1,4-diboronic acid (0.663 g, $4.0 \mathrm{mmol}), \mathrm{K}_{2} \mathrm{CO}_{3}(12 \mathrm{~mL}, 2.0$ $\mathrm{M}), \mathrm{N}, \mathrm{N}$-dimethylformamide $(80 \mathrm{~mL})$, and $\left[\mathrm{Pd}\left(\mathrm{PPh}_{3}\right)_{4}\right](60 \mathrm{mg})$ were used in this polymerization. After workup and Soxhlet extraction with chloroform, the product was obtained as a green powder (819 $\mathrm{mg}, 71 \%)$. Anal. Calcd for $\left(\mathrm{C}_{16} \mathrm{H}_{10} \mathrm{~N}_{2}\right)_{n}$ : C, 83.46; H, 4.38; N, $12.17 \%$; Found C, $70.75 ; \mathrm{H}, 4.05 ; \mathrm{N}, 10.10 \%$.

Synthesis of P31S. 2-Bromopyridine-5-boronic acid pinacol ester (1.13 g, $4.0 \mathrm{mmol}), \mathrm{K}_{2} \mathrm{CO}_{3}(8 \mathrm{~mL}, 2.0 \mathrm{M}), \mathrm{N}, \mathrm{N}$-dimethylformamide $(40 \mathrm{~mL})$, and $\left[\mathrm{Pd}\left(\mathrm{PPh}_{3}\right)_{4}\right](20 \mathrm{mg})$ were used in this polymerization. After workup and Soxhlet extraction with chloroform, the product was obtained as a dark green powder $(202 \mathrm{mg}, 66 \%)$. Anal. Calcd for $\left(\mathrm{C}_{5} \mathrm{H}_{3} \mathrm{~N}\right)_{n}: \mathrm{C}, 77.91 ; \mathrm{H}, 3.92 ; \mathrm{N}, 18.17 \%$; Found $\mathrm{C}, 72.55 ; \mathrm{H}, 3.99 ; \mathrm{N}$, $16.60 \%$.

Hydrogen Evolution Measurements. A flask was charged with the polymer powder $(25 \mathrm{mg})$, water, triethylamine, and methanol (1:1:1 vol. mixture, $25 \mathrm{~mL})$ and sealed with a septum. The resulting suspension was ultrasonicated until the photocatalyst was dispersed before degassing thoroughly by $\mathrm{N}_{2}$ bubbling for $30 \mathrm{~min}$. The reaction mixture was illuminated with a $300 \mathrm{~W}$ Newport Xe light-source (Model: 6258, Ozone free) for the time specified at a fixed distance under atmospheric pressure. The Xe-lamp was cooled by water circulating through a metal jacket. Gas samples were taken with a gastight syringe and run on a Bruker 450-GC gas chromatograph equipped with a Molecular Sieve 13X 60-80 mesh $1.5 \mathrm{~m} \times 1 / 8$ in. $\times 2$ $\mathrm{mm}$ ss column at $50{ }^{\circ} \mathrm{C}$ with an Ar flow of $40 \mathrm{~mL} \mathrm{~min}{ }^{-1}$. Hydrogen was detected with a thermal conductivity detector, referencing against standard gases with known concentrations of hydrogen. Hydrogen dissolved in the reaction mixture was not measured, and the pressure increase generated by the evolved hydrogen was neglected in the calculations. The rates were determined from a linear regression fit, and the error is given as the standard deviation of the amount of 
<smiles>Cc1ccc(C(C)(C)C)cc1</smiles>

P1<smiles>Cc1ccc(-c2ccc(C(C)(C)C)cc2)nc1</smiles>

P24<smiles>Cc1cnc(-c2ccc(C(C)(C)C)cc2)cn1</smiles>

P28<smiles>CC1(C)C=CC[C](C(C)(C)C)S1</smiles>

P17<smiles>CC(C)(C)c1ccc(-c2cncc(C(C)(C)C)c2)cc1</smiles>

P25

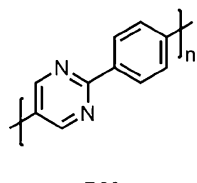<smiles>CC1(C)C=CC[C](C(C)(C)C)N1</smiles>

P22<smiles>CC(C)(C)c1ccc(-c2cccc(C(C)(C)C)n2)cc1</smiles>

P26

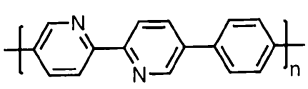

P30<smiles>Cc1ccc(-c2ccc(N(c3ccccc3)c3ccc(C)cc3)cc2)cc1</smiles>

P23

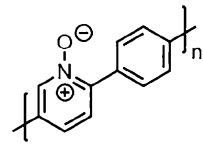

P27

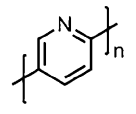

P31

Figure 1. Structures of the polymer photocatalysts studied here.

hydrogen evolved. No hydrogen evolution was observed for a mixture of water/methanol/triethylamine under $\lambda>295 \mathrm{~nm}$ illumination in absence of a photocatalyst. For the EQE experiments $\mathrm{H}_{2}$ evolution was measured using LEDs as the light source.

Computational Screening. To study the thermodynamic driving forces for proton reduction and triethylamine oxidation, as well as the extent of visible light absorption and the exciton binding energies for P1, P17, and P22-P34, we use a computational approach we have applied previously to other polymer series. ${ }^{52,53,67,68}$ We also calculate the solvation energy of the polymers in water as a predictor of the polymer wettability.

Polymer Structure Generation. Oligomeric models of the different polymers containing the equivalent of 12 phenyl units (e.g., Phenylene $_{12}$ and ((Phenylene)(Pyridine $\left.)\right)_{6}$ were constructed by hand. This length of 12 phenyl equivalent units was chosen because previous work showed approximate convergence of thermodynamic properties for such oligomers. ${ }^{67}$ The resulting oligomeric models then undergo a conformer search and energy minimization process using Schödinger PLC's Macromodel software ${ }^{71}$ in conjunction with the OPLS2005 ${ }^{72}$ force field. We typically used a combination of 10000 search steps and minimum and maximum low-mode move distances of 3 and $6 \AA$, respectively. All the structures located within an energy window of $100 \mathrm{~kJ} \mathrm{~mol}^{-1}$ relative to the lowest energy conformer were saved. The lowest energy confomers were then reoptimized using density functional theory (DFT) calculations, using the $\mathrm{B}^{2} \mathrm{LYP}^{73,74}$ density functional and DZP ${ }^{75}$ basis set, within Turbomole $7.01 .^{76-78}$

Thermodynamic Driving Force Calculations. To assess the ability of a given polymer to perform the necessary chemistry for hydrogen evolution, the thermodynamic driving force of the polymer for proton reduction and triethylamine oxidation were analyzed in terms of the potentials associated with free electrons (EA), holes (IP), and excitons (EA* and $\left.\mathrm{IP}^{*}\right)$, relative to those of the corresponding solution half reactions. To obtain these potentials, we employ our previously developed $\Delta \mathrm{SCF}$ approach, ${ }^{67,79}$ rooted in (time-dependent) density functional theory ((TD-)DFT). Using the COSMO ${ }^{80,81}$ solvation model as an approximation to the dielectric environment of the polymer chain at the polymer-solution interface, this approach is applied to the lowest energy conformers obtained via the conformer screening process outlined above. Within this $\triangle S C F$ approach, the $\mathrm{B} \mathrm{LYP}^{73,74}$ density functional and $\mathrm{DZP}^{75}$ basis set are employed, which we have previously showed to predict accurate potentials when compared with available experimental photoelectron spectros- copy data. ${ }^{79}$ Potentials for solution half reactions are discussed in Section 14 of the Supporting Information. All potential and spectra calculations, discussed below, use Turbomole $7.01 .^{76,82,83}$

Optical Gap Calculations. The extent of light absorption for each polymer is estimated by extracting optical gaps from calculated vertical excitation spectra (TD-B3LYP/DZP). Here, we define the optical gap as the lowest vertical excitation with nonzero oscillator strength. These calculations are based on full (TD-)DFT, while the $\mathrm{EA}^{*}$ and IP* calculations use the Tamn-Dancoff ${ }^{84}$ approximation for reasons of stability. ${ }^{85}$

Solvation Energy Calculations. We calculated the solvation energy of the different oligomeric models as a predictor of the wettability of the corresponding polymers. Solvation energies were obtained by single point calculations on the B3LYP/COSMO optimized geometries with and without the SMD solvation model. ${ }^{86}$ All solvation energy calculations used the Gaussian09 code, ${ }^{87}$ the B3LYP density functional, and the $6-31 \mathrm{G}^{* *}$ basis set. $^{85}$

\section{RESULTS AND DISCUSSION}

Synthesis and Characterization. The photocatalysts were synthesized from commercial monomers using $\operatorname{Pd}(0)$ catalyzed Suzuki-Miyaura polycondensation at $150{ }^{\circ} \mathrm{C}$ in $\mathrm{N}, \mathrm{N}$ dimethylformamide for 2 days (Figure 1, P23-P31). ${ }^{42}$ After workup and Soxhlet extraction with chloroform, all materials were obtained as insoluble powders, which precludes molecular weight determination. ${ }^{52}$

All materials were characterized by elemental analysis, Fourier-transform infrared spectroscopy (FT-IR), thermogravimetric analysis (TGA), scanning electron microscope (SEM), energy-dispersive X-ray spectroscopy (EDX), and powder X-ray diffraction (PXRD). TGA showed that all materials were stable up to around $350{ }^{\circ} \mathrm{C}$ under air, and SEM revealed particles with varied morphologies of typically 1 to 5 $\mu \mathrm{m}$ size that are fused together into larger aggregates. All materials contain bromine, which most likely is present in the materials as end-groups. The poly(triphenylamine-co-phenylene) polymer P23 was found to be amorphous via PXRD as commonly observed for this material class, ${ }^{70,88}$ while all other materials show weak and broad reflections in their PXRD 
spectra as it is typical for semicrystalline materials. Matrixassisted laser desorption/ionization time-of-flight mass spectrometry (MALDI-ToF MS, Figures S-2-S-6) was performed for P23, P24, P28, P30, and P31 allowing the observation of distinct repeat units for all studied materials. Similar to a previous study ${ }^{53}$ we see for P24, P28, P30, and P31 masses between 600 and $2700 \mathrm{~m} / z$. This indicates that the molecular weights are low but in a similar range for these materials. For P23 we see masses up to $3200 \mathrm{~m} / z$ and a shift of the pseudo mass distribution to higher masses, which can be explained by the fact that triarylamines do undergo easier ionization. ${ }^{89}$

Optical Properties. As shown in Table 1, poly(thiophene) and poly(pyrrole) (P17 and P22) have the most red-shifted

\section{Table 1. Optical Gap and Hydrogen Evolution Rates}

$\begin{array}{cccc}\text { Material } & \begin{array}{c}\text { optical gap, } \\ \mathrm{eV}\end{array} & \begin{array}{c}\mathrm{HER}^{b} \\ \lambda>420 \mathrm{~nm} / \mu \mathrm{mol} \mathrm{h}^{-1}\end{array} & \begin{array}{c}\text { HER, } \\ \lambda>295 \mathrm{~nm} / \mu \mathrm{mol} \mathrm{h}^{-1}\end{array} \\ \text { P1 } & 2.78 & 1.6( \pm 0.1) & 6.0( \pm 0.2) \\ \text { P17 } & 1.89 & >0.1 & 0.25( \pm 0.03) \\ \text { P22 } & 2.06 & 0 & >0.1 \\ \text { P23 } & 2.70 & 0 & >0.1 \\ \text { P24 } & 2.76 & 14.2( \pm 0.5) & 27.8( \pm 0.8) \\ \text { P25 } & 3.29 & >0.1 & 3.9( \pm 0.2) \\ \text { P26 } & 3.22 & >0.1 & 0.65( \pm 0.02) \\ \text { P27 } & 2.65 & 0.6( \pm 0.2) & 4.2( \pm 0.3) \\ \text { P28 } & 2.45 & 24.0( \pm 0.7) & 33.6( \pm 1.6) \\ \text { P29 } & 2.73 & 1.6( \pm 0.1) & 4.3( \pm 0.2) \\ \text { P30 } & 2.72 & 7.4( \pm 0.4) & 17.1( \pm 0.7) \\ \text { P31 } & 2.51 & 15.2( \pm 0.6) & 37.5( \pm 1.1)\end{array}$

${ }^{a}$ The optical gap was determined from the UV-vis absorption spectrum. ${ }^{b}$ Hydrogen evolution rate for $25 \mathrm{mg}$ of photocatalyst in a 1:1:1 mixture of $\mathrm{H}_{2} \mathrm{O} / \mathrm{MeOH} /$ triethylamine using a suitable filter (300 W Xe light source).

onset of light absorption (optical gap) as measured in the solid state and start absorbing in the red part of the spectrum. The meta-linked pyridine copolymers (P25 and P26), by contrast, have the most blue-shifted optical gap and only start absorbing light in the (ultra)violet. The other polymers lie in between these two extremes. (TD-)DFT calculations (Table S-6), where the optical gap is modeled as the lowest vertical singletto-singlet excitation with a nonzero oscillator strength, paint a similar picture with some minor differences. (TD-)DFT calculations yield-in contrast to experiment-a slightly larger optical gap for P30 than for P24. However, the small differences in experimental optical gap values among P1, P24, and P30 likely fall within the range of error expected for the method used to extract the optical gap values from the spectra. From a theoretical perspective, the small differences in the optical gap values of the three polymers are of the same order of magnitude that would be expected for differences in the optical gap values for different conformers of a single polymer. $^{90}$

The block-like spectra found for the polymers (see Figure 2) are rather different from those predicted by (TD-)DFT, where generally the lowest energy singlet-to-singlet excitation carries most of the intensity in the visible and near-UV part of the spectrum. Part of this is due to vibrational broadening, as well as the likely polydispersity of the polymers and solid-state packing effects. We believe, however, that the overall block-like shape can only be explained by repeated transmission in the powder sample due to scattering, resulting in absorption of

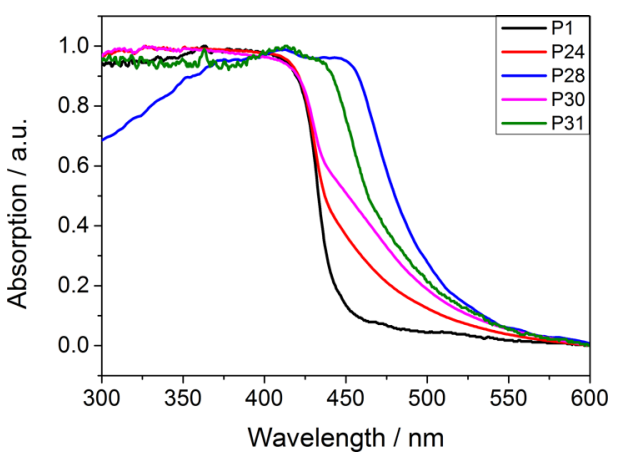

Figure 2. Absorption spectra of P1, P24, P28, P30, and P31 measured in the solid state.

most of the light, irrespective of the oscillator strength of excitations. $^{91}$ Studies of the EQE of P28 for different wavelengths (see Figure 6, vide infra), as well as wavelengthdependent hydrogen evolution measurements for the same material using different band-pass filters (see Figure S-44), demonstrate that these block-like shaped absorption spectra are not an artifact of the UV-vis measurement conditions but representative for the polymer under the photocatalytic operating conditions. Both the EQE values and the wavelength-dependent hydrogen evolution rates track the shape of the P28 UV-vis spectrum.

The photoluminescence properties of all polymers were studied, and all materials are emissive upon excitation with UV light $\left(\lambda_{\text {exc }}=360 \mathrm{~nm}\right)$. The lifetime of the excited state of the polymers in THF suspension was estimated using timecorrelated single photon counting (TCSPC, section 8 of the Supporting Information). As in previous studies ${ }^{43,49}$ we found that estimated average lifetimes are short, with P24 having the shortest lifetime ( $0.69 \mathrm{~ns})$, followed by P30 (0.70 ns) and P31 (0.73 ns). A longer lifetime was measured for P1 (0.93 ns) and even longer for P28 (2.73 ns).

Polymer Potentials and the Thermodynamic Driving Force for Reduction and Oxidation. The IP, EA, IP*, and $\mathrm{EA}^{*}$ values of a polymer are difficult to measure experimentally, especially under operating conditions in the presence of water or a water-based sacrificial hole donor system. ${ }^{79}$ We therefore calculated these potentials using a combination of DFT and (TD-)DFT. Figure 3 shows the such calculated potentials for the range of polymers considered, as well as the solution potentials for proton reduction and TEA oxidation at $\mathrm{pH} 11.5$ (approximate $\mathrm{pH}$ of a TEA in water solution) and proton reduction and water oxidation at $\mathrm{pH} 7$.

Considering the data in Figure 3, it is clear that all polymers considered are predicted to have a significant thermodynamic driving force for proton reduction at both $\mathrm{pH}$ values. All polymers except P22 also have a significant predicted thermodynamic driving force for the overall, two-hole oxidation of TEA but the driving force for the one-hole intermediate oxidation step is considerably smaller and, for some polymers, endergonic. As such, assuming that the TEA oxidation is an outer-sphere electron transfer process, this intermediate step might act as a thermodynamic barrier. Most nitrogen containing materials barring P22 and P23 are predicted to have a moderate driving force for the overall oxidation of water.

Wettability. The wettability of the most active polymers was studied experimentally in terms of the contact angle with water (Figure 4) and was also probed computationally using 
a
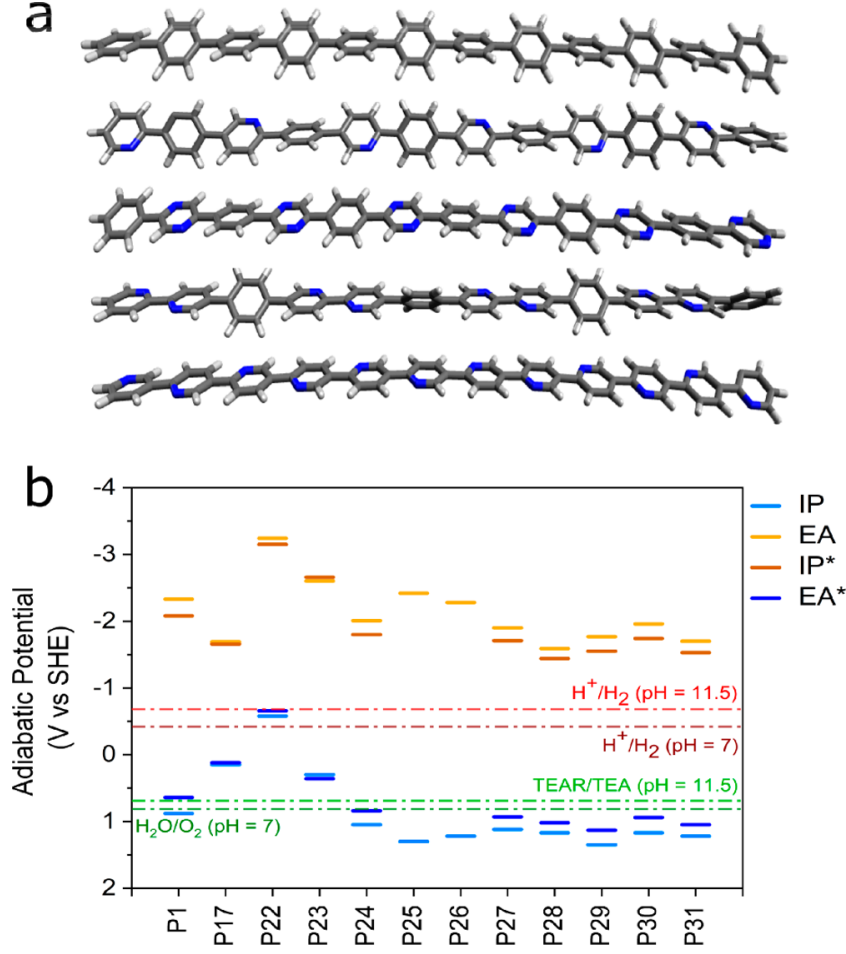

Figure 3. (a) B3LYP/DZP optimized structures of oligomer models representing polymers P1, P24, P28, P30, and P31. (b) Predicted charge carrier (IP, EA) and exciton (IP*, EA*) potentials of polymer materials considered. For guidance, various potentials for solution reactions are also given: reduction potential for hydrogen and oxidation potential for water at $\mathrm{pH} 7$; reduction potential for hydrogen and oxidation potential for the SED (TEA) at $\mathrm{pH}$ 11.5.

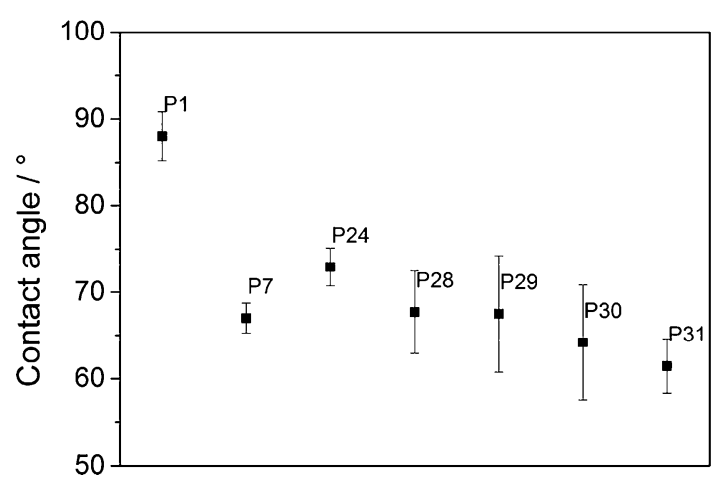

Figure 4. Contact angles for P1, P7, P24, P28, P29, P30, and P31 against water. $\mathrm{P}^{51}$ is a copolymer of phenylene and dibenzo $[b, d]$ thiophene, included for comparison.

solvation energy calculations for the polymers in water (see Table S-6). In the case of water, both approaches gave similar results; adding increasing amounts of nitrogen into the polymers improves their wettability. When the TEA/MeOH/ water mixture was used, the contact angles were very low and could not be measured for all samples, suggesting that the difference in wettability between the different polymers in the photocatalysis mixture is much less pronounced.

Surface Area and Particle Size. The nitrogen uptake of $\mathrm{P} 1, \mathrm{P} 24, \mathrm{P} 28, \mathrm{P} 30$, and P31 was measured at $77 \mathrm{~K}$, and apparent Brunauer-Emmett-Teller surface areas $\left(\mathrm{SA}_{\mathrm{BET}}\right)$ of $29 \mathrm{~m}^{2} \mathrm{~g}^{-1}$ for P1, $23 \mathrm{~m}^{2} \mathrm{~g}^{-1}$ for P24, $69 \mathrm{~m}^{2} \mathrm{~g}^{-1}$ for P28, $25 \mathrm{~m}^{2}$ $\mathrm{g}^{-1}$ for $\mathrm{P} 30$, and $17 \mathrm{~m}^{2} \mathrm{~g}^{-1}$ for P31 were determined (S-27).
These values are typical for linear conjugated polymers and similar to what we have observed previously. ${ }^{53}$ Only P28 shows uptake at low pressures, which indicates a low level of microporosity. Static light scattering experiments were performed in water/methanol/TEA mixtures (S-28), which showed some variation in the particle size distribution/similar sizes. Sauter mean diameters between 4 and $10.2 \mu \mathrm{m}$ were measured for P1, P28, P30, and P31. Only P24 has a fraction of smaller particles which results in a smaller Sauter mean diameter of $2.46 \mu \mathrm{m}$; however, the multimodal broad distribution results in a larger volume mean diameter of 6.9 $\mu \mathrm{m}$.

Photocatalytic Hydrogen Production. All materials were tested for their performance as photocatalysts for the reduction of protons in the presence of a SED. Mixtures of water, triethylamine (TEA), and methanol were used, where TEA acts as the SED and methanol is added to aid mixing of the TEA with water. In all cases no cocatalyst was added; however, residual palladium $(0.17-0.90 \mathrm{wt} \%)$ was found in all materials as they were made via $\operatorname{Pd}(0)$-catalyzed SuzukiMiyaura polycondensation (see Table S-1). ${ }^{42}$ Palladium has been shown previously to act as a cocatalyst for hydrogen evolution in conjugated microporous polymers, ${ }^{48}$ covalent triazine-based frameworks, ${ }^{57}$ and carbon nitride. ${ }^{17}$ Poly(thiophene $)^{92}$ P17 and poly(pyrrole) ${ }^{20}$ P22 show little activity even under broadband illumination $(\lambda>295 \mathrm{~nm})$. Similarly, the polytriphenylamine-co-phenylene polymer P23 shows very little activity. When nitrogen atoms were introduced into the benzene rings, a different behavior was observed: The 2,5substituted pyridine-co-phenylene polymer shows good activity under visible light $\left(14.2 \mu \mathrm{mol} \mathrm{h}^{-1}, \lambda>420 \mathrm{~nm}\right)$ and broadband illumination $\left(27.8 \mu \mathrm{mol} \mathrm{h}^{-1}, \lambda>295 \mathrm{~nm}\right)$, compared to poly ( $p$-phenylene) (P1). The introduction of meta-linkages in both P25 and P26 results in an almost complete loss of activity under visible light $(\lambda>420 \mathrm{~nm})$. Also under broadband illumination $(\lambda>295 \mathrm{~nm})$ the activity is low with hydrogen evolution rates of $3.9 \mu \mathrm{mol} \mathrm{h}^{-1}$ for P25 and $0.7 \mu \mathrm{mol} \mathrm{h}^{-1}$ for P26 compared to the 1,4-linked analogue P24. The oxidation of the pyridine nitrogen also lowers the activity under both visible light $\left(0.6 \mu \mathrm{mol} \mathrm{h}^{-1}, \lambda>420 \mathrm{~nm}\right)$ and broadband illumination $\left(4.2 \mu \mathrm{mol} \mathrm{h}^{-1}, \lambda>295 \mathrm{~nm}\right)$.

The introduction of a second nitrogen into the ring results in a significantly enhanced hydrogen production rate for P28 $\left(24.0 \mu \mathrm{mol} \mathrm{h}^{-1}, \lambda>420 \mathrm{~nm}\right.$, equivalent to $\left.960 \mu \mathrm{mol} \mathrm{g}^{-1} \mathrm{~h}^{-1}\right)$ compared to P24 under visible light (Figure 5). Under broadband illumination the difference in their hydrogen evolution rates is much smaller $(\lambda>295 \mathrm{~nm}, 33.6$ vs 27.8 $\left.\mu \mathrm{mol} \mathrm{h}{ }^{-1}\right)$. The bipyridine-co-phenylene polymer P30 also shows good performance with a hydrogen evolution rate of 7.4 $\mu \mathrm{mol} \mathrm{h}{ }^{-1}$ under $\lambda>420 \mathrm{~nm}$ and $17.1 \mu \mathrm{mol} \mathrm{h}^{-1}$ under broadband illumination $(\lambda>295 \mathrm{~nm})$. The homopolymer of P31, finally, has a good photocatalytic activity with rates of $15.2 \mu \mathrm{mol} \mathrm{h}^{-1}$ under visible light and $37.5 \mu \mathrm{mol} \mathrm{h}^{-1}$ under broadband illumination, which is comparable to the copolymer with phenylene P24.

The measurements under visible and broadband illumination can be compared with those performed under UV light only. Photocatalytic experiments with a U-340 filter (transmissive in the range of 255 to $395 \mathrm{~nm}$ ) gives rates of $8.2 \mu \mathrm{mol}$ $\mathrm{h}^{-1}$ for P1, $9.1 \mu \mathrm{mol} \mathrm{h}^{-1}$ for P24, $10.2 \mu \mathrm{mol} \mathrm{h}^{-1}$ for P28, and $9.8 \mu \mathrm{mol} \mathrm{h}^{-1}$ for P30 and a higher rate of $24.1 \mu \mathrm{mol} \mathrm{h}^{-1}$ for P31 (see S-33). 


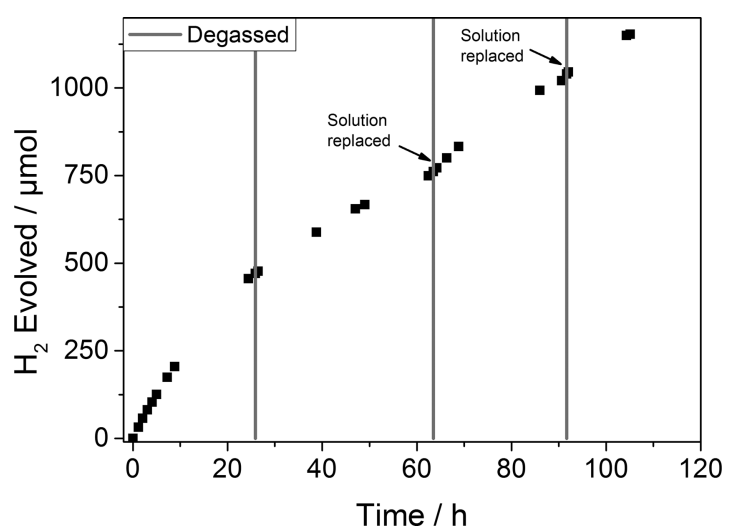

Figure 5. Extended hydrogen evolution experiment for P28 under visible light $(\lambda>420 \mathrm{~nm})$ from a $\mathrm{H}_{2} \mathrm{O} / \mathrm{MeOH} / \mathrm{TEA}$ mixture for a total of $105 \mathrm{~h}$. The solution was intermittently degassed, and after 63 and $92 \mathrm{~h}$ the $\mathrm{H}_{2} \mathrm{O} / \mathrm{MeOH} / \mathrm{TEA}$ mixture was replaced.

On/off photocurrent measurements (S-45) for P1, P28, and P3 show an increased response going from P1 to P31 and P28 under visible light. The same order is observed for the activity in suspension photocatalysis experiments.

Longer-term stability of P28 was tested by using the photocatalyst for a total of $105 \mathrm{~h}$ under visible light $(\lambda>420$ $\mathrm{nm}$ ) irradiation (see Figure 2). The performance dropped slightly over the course of the run but could be recovered when the water/methanol/TEA mixture was replaced. Characterization of the material after the experiment showed no noticeable differences in its FT-IR, UV-vis, photoluminescence, and PXRD spectra. This suggests that the drop-off in activity for these conjugated polymers might in some cases be related to changes in the sacrificial donor solution, or possibly buildup of material on the polymer surface, rather than decomposition of the polymer itself, at least over time scales of the order of $100 \mathrm{~h}$.

External quantum efficiencies (EQE) were estimated for polymer P28 using monochromatic light. At $420 \mathrm{~nm}$ an EQE of $6.7 \%$ was determined in a water $/ \mathrm{MeOH} / \mathrm{TEA}$ mixture, which is higher than previously reported for $\mathrm{P} 1\left(\mathrm{EQE}_{420}=\right.$ $0.4 \%$ ) under the same conditions, ${ }^{52} \mathrm{Pt}$ modified tricyanobenzene centered phenylenevinylene-co-terphenylene polymer network OB-POP-3 $\left(\mathrm{EQE}_{420}=2.0 \%\right)^{93}$ in a triethanolamine mixture, or $\mathrm{Pt}$ modified phenylene-benzothiadiazole-co-polymer B-BT-1,4 $\left(\mathrm{EQE}_{420}=4.0 \%\right)^{47}$ in a triethanolamine mixture, and similar to a phenylene-dibenzo $[b, d]$ thiphene-5,5-dioxideco-polymer P7 $\left(\mathrm{EQE}_{420}=7.2 \%\right)$ using a water $/ \mathrm{MeOH} / \mathrm{TEA}$ mixture. $^{52}$ In this context it is important to note that EQEs are scavenger dependent as the photocatalyst performance depends on the efficiency of the hole quenching process. ${ }^{47}$

The EQE of P28 is reduced to $4.5 \%$ at $470 \mathrm{~nm}$ and only $0.5 \%$ at $550 \mathrm{~nm}$, and this shows that the efficiency tracks the absorption profile of the polymer and that the process is indeed driven by the absorption of light (Figure 6).

Hydrogen production measurements for P1 and P28 under visible illumination using an aqueous solution of $\mathrm{Na}_{2} \mathrm{~S}$ and $\mathrm{Na}_{2} \mathrm{SO}_{3}$ as a sacrificial hole scavenger rather than the water/ $\mathrm{MeOH} / \mathrm{TEA}$ mixture showed much reduced activities of $>0.1$ and $6.8 \mu \mathrm{mol} \mathrm{h}^{-1}$, respectively. We also studied these materials for oxygen evolution using aqueous solutions of $\mathrm{AgNO}_{3}$ but were unable to find conditions that showed significant levels of $\mathrm{O}_{2}$ production.

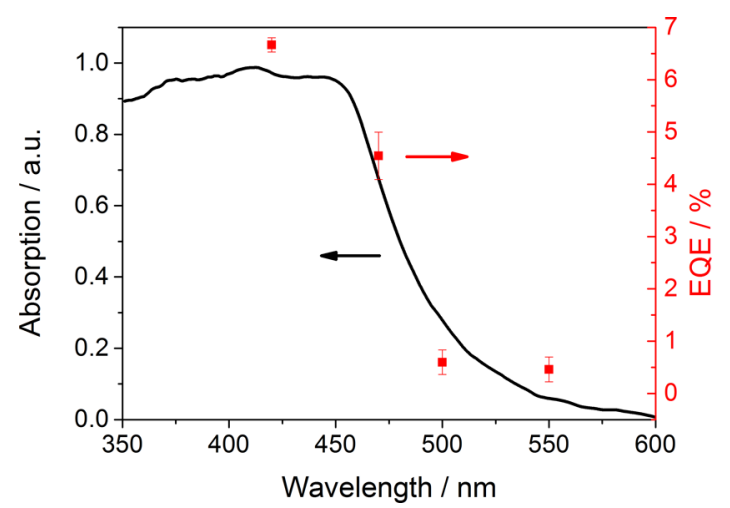

Figure 6. Absorption spectrum and external quantum efficiency (EQE) measured with monochromatic light in a water/MeOH/TEA mixture for P28.

\section{DISCUSSION}

Conceptually, the activity of the different polymers finds it origin in the synergistic combination of a series of material properties. First, there is the overlap of the material's optical absorption spectrum and the light source. The more photons that are absorbed, the more protons can be reduced and holescavengers oxidized. Second, there is the thermodynamic ability of free charge carriers and excitons to drive both solution reactions. If there is no driving force for one or both reactions, hydrogen evolution will not take place. Moreover, larger driving forces are likely to translate into higher reaction rates. Finally, the more wettable a polymer, the better the contact between polymer and solution, which again should benefit reaction rates. Not all of these properties necessarily vary in the same way with polymer composition. Also, depending on the reaction conditions, different properties might dominate the hydrogen evolution rate (e.g., these polymers are wetted far better by the reaction solution than by pure water, which would represent a different regime).

We will now analyze the hydrogen evolution rates of the different materials in terms of these various properties. First, the reason that five-membered heterocycle-based polymers, P17 and P22, evolve little or no hydrogen probably stems from their very shallow IP/EA* potentials, as predicted by (TD)DFT (see Figure 3); that is, compared to the other polymers, the driving force for sacrificial hole scavenger oxidation is much smaller, especially in the case of P22. We ascribe this to the electron rich nature of five-membered heterocycle-based polymers. P17 and P22 also have a red-shifted optical gap compared to the other polymers, and hence they absorb more photons. However, this is evidently of limited use when, at the same time, the material struggles to oxide the electron donor. The meta-polymers P25 and P26 present the opposite case: both are predicted to have a significant driving force for the oxidation of TEA, in line with the fact that six-membered heterocycles are electron poor, but the cross-conjugation resulting from their meta-connectivity means that these materials now only absorb in the ultraviolet. As a result, hydrogen evolution is limited by light absorption. Hence, P17 and P22 on the one hand and P25 and P26 on the other illustrate how photocatalytic activity is often the result of tradeoffs between properties, whereby optimizing one property in isolation can impact other properties in a negative way. ${ }^{53}$

$\mathrm{P} 1, \mathrm{P} 24, \mathrm{P} 28, \mathrm{P} 30$, and P31 lie in the middle of these extremes, absorbing both a reasonable amount of light, 
especially P31 and P28, as well as having a significant thermodynamic driving force for the overall oxidation of TEA and a small-moderate driving force for the intermediate one-hole oxidation step. This is therefore the group of polymers with the largest hydrogen production rates. P28 is the most active material under visible illumination, in line with the fact that it has the most red-shifted optical gap and (together with P31) the largest thermodynamic driving force for TEA oxidation.

Compared to P28, the moderate visible light performance of P31 is harder to explain based on consideration of driving force and light absorption alone, especially considering that, under broadband illumination, P31 is the most active. Part of the explanation might lie in the longer excited-state lifetime of P28 compared to P31, as measured by TCPSC experiments, which suggests that competition of de-excitation might be more prominent for P31 than P28. Also, the specific combination of the more porous nature of $\mathrm{P} 28$ relative to the other polymers and its wettability might further contribute to the increased performance of P28. Finally, the fact that the absorption of P31 and most other polymers stays constant in the near-UV, while that of P28 decreases significantly below $400 \mathrm{~nm}$, might explain the difference in ranking of P28 and P31 under visible and broadband illumination.

The lack of real activity for P23, the triphenylamine copolymer, is in line with the fact that it is predicted to have relatively shallow IP/EA* values, worse than P1 and not much better than P17, combined with only a moderate optical gap. The lack of activity for P27, the pyridin-1-ium-1-olate-phenylco-polymer, is more surprising since it has both adequate IP/

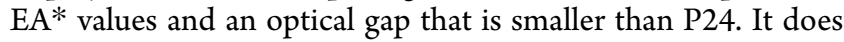
suggest, however, that if oxidation of pyridinic nitrogen atoms would occur during illumination in the presence of water it would not improve the activity of a polymer.

We observe no clear correlation between particle size and hydrogen evolution rate for the different materials. In part this might be because the maximum difference in particle diameter between the different polymers is less than 1 order of magnitude.

Regarding the experiments for P1 and P28 using an aqueous solution of $\mathrm{Na}_{2} \mathrm{~S}$ and $\mathrm{Na}_{2} \mathrm{SO}_{3}$, we suspect that the observed reduction in hydrogen production relative to water $/ \mathrm{MeOH} /$ TEA mixtures is to a large degree related to the low wettability of the polymers in pure water (or in salt solutions), as reflected by the contact angle measurements. This is also probably the reason why the more wettable of the two polymers, P28, still has a reasonable hydrogen production rate while the less wettable, P1, does not.

Finally, the lack of firm experimental evidence for water oxidation and overall water splitting activity for polymers such as P28 and P31 does based on the calculations not appear to be caused by a lack of driving force for the overall water oxidation reaction. More likely, the problem is the relatively poor wettability of the polymers and/or the absence of a suitable cocatalyst to enhance the kinetics. A further contributing factor in the case of overall water splitting might be more pronounced competition between oxidation and electron-hole recombination when performing the fourhole water oxidation relative to the two-hole TEA oxidation.

\section{CONCLUSIONS}

The introduction of nitrogen containing, electron-poor, heterocyclic aromatics into unbranched conjugated polymers results in a significant increase of their photocatalytic performance. In contrast, the introduction of electron-rich heterocycles is found to significantly reduce performance. These observations seem to be linked to an increase and decrease in the thermodynamic driving force for sacrificial electron donor oxidation, induced by the incorporation of electron-poor and electron-rich units, respectively. Introducing electron-rich monomer units does lead to a red-shift in the optical gap and, therefore, a better overlap with the solar spectrum, but the associated reduction in driving force for sacrificial electron donor oxidation outweighs any potential gains in photocatalytic activity. This highlights that the optimization of a single property in isolation is a poor strategy for improving overall photocatalytic activity.

\section{ASSOCIATED CONTENT}

\section{S Supporting Information}

The Supporting Information is available free of charge on the ACS Publications website at DOI: 10.1021/acs.chemmater.8b02501.

FT-IR spectra, nitrogen sorption isotherms, static light scattering results, MALDI-ToF MS spectra, UV-vis spectra, PL spectra, TGA traces, SEM images, EDX data, PXRD, TCSPC experiments, photocatalysis experiments, photocurrent experiments, contact angle measurements, and computational results (PDF)

\section{AUTHOR INFORMATION}

\section{Corresponding Authors}

*(R.S.S.) E-mail: ssprick@liverpool.ac.uk.

*(M.A.Z.) E-mail: m.zwijnenburg@ucl.ac.uk. ORCID

Reiner Sebastian Sprick: 0000-0002-5389-2706

Yang Bai: 0000-0002-1643-3770

Andrew I. Cooper: 0000-0003-0201-1021

Martijn A. Zwijnenburg: 0000-0001-5291-2130

Notes

The authors declare no competing financial interest.

\section{ACKNOWLEDGMENTS}

We thank the Engineering and Physical Sciences Research Council (EPSRC) for financial support under Grants EP/ N004884/1 and EP/I004424/1. Y.B. thanks the China Scholarship Council for a Ph.D. studentship. Dr. Linjiang Chen, Yiou Wang, Dan Kong, and Dr. Junwang Tang are kindly acknowledged for discussion. Lunjie Liu and Catherine Aitchison are acknowledged for help with photocurrent and SLS measurements.

\section{REFERENCES}

(1) Ogden, J. M. Prospect for Building a Hydrogen Energy Infrastructure. Annu. Rev. Energy Environ. 1999, 24, 227-279.

(2) Das, V.; Padmanaban, S.; Venkitusamy, K.; Selvamuthukumaran, R.; Blaabjerg, F.; Siano, P. Recent Advances and Challenges of fuel cell based power system architecturES and control - a Review. Renewable Sustainable Energy Rev. 2017, 73, 10-18.

(3) White, C.; Steeper, R.; Lutz, A. The Hydrogen-Fueled Internal Combustion Engine: A Technical Review. Int. J. Hydrogen Energy 2006, 31, 1292-1305.

(4) Mehra, R. K.; Duan, H.; Juknelevičius, R.; Ma, F.; Li, J. Progress in Hydrogen Enriched Compressed Natural Gas (HCNG) Internal 
Combustion Engines - A Comprehensive Review. Renewable Sustainable Energy Rev. 2017, 80, 1458-1498.

(5) Kudo, A.; Miseki, Y. Heterogeneous Photocatalyst Materials for Water Splitting. Chem. Soc. Rev. 2009, 38, 253-278.

(6) Hisatomi, T.; Domen, K. Progress in the Demonstration and Understanding of Water Splitting Using Particulate Photocatalysts. Curr. Opin. Electrochem. 2017, 2, 148-154.

(7) Yanagida, S.; Kabumoto, A.; Mizumoto, K.; Pac, C.; Yoshino, K. Poly ( $p$-phenylene)-Catalysed Photoreduction of Water to Hydrogen. J. Chem. Soc., Chem. Commun. 1985, 0, 474-475.

(8) Shibata, T.; Kabumoto, A.; Shiragami, T.; Ishitani, O.; Pac, C.; Yanagida, S. Novel visible-light-driven photocatalyst. Poly( $p$-phenylene)-Catalyzed Photoreductions of Water, Carbonyl Compounds, and Olefins. J. Phys. Chem. 1990, 94, 2068-2076.

(9) Matsuoka, S.; Fujii, H.; Yamada, T.; Pac, C.; Ishida, a; Takamuku, S.; Kusaba, M.; Nakashima, N.; Yanagida, S.; Hashimoto, K.; Sakata, T.; et al. Photocatalysis of Oligo(para-phenylenes) Photoreductive Production of Hydrogen and Ethanol in Aqueous Triethylamine. J. Phys. Chem. 1991, 95, 5802-5808.

(10) Yanagida, S.; Matsuoka, S. Effective Photoreduction of $\mathrm{CO}_{2}$ Catalyzed by Oligo( $p$-phenylenes). Proc. SPIE 1992, 1729, 243-250.

(11) Wang, X.; Maeda, K.; Thomas, A.; Takanabe, K.; Xin, G.; Carlsson, J. M.; Domen, K.; Antonietti, M. A Metal-Free Polymeric Photocatalyst for Hydrogen Production from Water Under Visible Light. Nat. Mater. 2009, 8, 76-80.

(12) Wang, X.; Blechert, S.; Antonietti, M. Polymeric Graphitic Carbon Nitride for Heterogeneous Photocatalysis. ACS Catal. 2012, 2, 1596-1606.

(13) Cao, S.; Yu, J. G- $\mathrm{C}_{3} \mathrm{~N}_{4}$-Based Photocatalysts for Hydrogen Generation. J. Phys. Chem. Lett. 2014, 5, 2101-2107.

(14) Ong, W.-J. J.; Tan, L.-L. L.; Ng, Y. H.; Yong, S.-T. T.; Chai, S.P. P. Graphitic Carbon Nitride $\left(\mathrm{g}-\mathrm{C}_{3} \mathrm{~N}_{4}\right)$-Based Photocatalysts for Artificial Photosynthesis and Environmental Remediation: Are We a Step Closer to Achieving Sustainability? Chem. Rev. 2016, 116, 71597329.

(15) Wen, J.; Xie, J.; Chen, X.; Li, X. A Review on g- $\mathrm{C}_{3} \mathrm{~N}_{4}$-Based Photocatalysts. Appl. Surf. Sci. 2017, 391, 72-123.

(16) Wang, X.; Maeda, K.; Chen, X.; Takanabe, K.; Domen, K.; Hou, Y.; Fu, X.; Antonietti, M. Polymer Semiconductors for Artificial Photosynthesis: Hydrogen Evolution by Mesoporous Graphitic Carbon Nitride With Visible Light. J. Am. Chem. Soc. 2009, 131, $1680-1681$.

(17) Maeda, K.; Wang, X.; Nishihara, Y.; Lu, D.; Antonietti, M.; Domen, K. Photocatalytic Activities of Graphitic Carbon Nitride Powder for Water Reduction and Oxidation Under Visible Light. J. Phys. Chem. C 2009, 113, 4940-4947.

(18) Zhang, J.; Chen, X.; Takanabe, K.; Maeda, K.; Domen, K.; Epping, J. D.; Fu, X.; Antonietti, M.; Wang, X. Synthesis of a Carbon Nitride Structure for Visible-Light Catalysis by Copolymerization. Angew. Chem., Int. Ed. 2010, 49, 441-444.

(19) Zhang, G.; Lan, Z.-A.; Lin, L.; Lin, S.; Wang, X. Overall Water Splitting by $\mathrm{Pt} / \mathrm{g}-\mathrm{C}_{3} \mathrm{~N}_{4}$ Photocatalysts Without Using Sacrificial Agents. Chem. Sci. 2016, 7, 3062-3066.

(20) Sui, Y.; Liu, J.; Zhang, Y.; Tian, X.; Chen, W. Dispersed Conductive Polymer Nanoparticles On Graphitic Carbon Nitride for Enhanced Solar-Driven Hydrogen Evolution from Pure Water. Nanoscale 2013, 5, 9150-9155.

(21) Schwinghammer, K.; Tuffy, B.; Mesch, M. B.; Wirnhier, E.; Martineau, C.; Taulelle, F.; Schnick, W.; Senker, J.; Lotsch, B. V. Triazine-Based Carbon Nitrides for Visible-Light-Driven Hydrogen Evolution. Angew. Chem., Int. Ed. 2013, 52, 2435-2439.

(22) Martin, D. J.; Qiu, K.; Shevlin, S. A.; Handoko, A. D.; Chen, X.; Guo, Z.; Tang, J. Highly Efficient Photocatalytic $\mathrm{H}_{2}$ Evolution from Water Using Visible Light and Structure-Controlled Graphitic Carbon Nitride. Angew. Chem., Int. Ed. 2014, 53, 9240-9245.

(23) Schwinghammer, K.; Mesch, M. B.; Duppel, V.; Ziegler, C.; Senker, J.; Lotsch, B. V. Crystalline Carbon Nitride Nanosheets for Improved Visible-Light Hydrogen Evolution. J. Am. Chem. Soc. 2014, 136, 1730-1733.
(24) Liu, J.; Liu, Y.; Liu, N.; Han, Y.; Zhang, X.; Huang, H.; Lifshitz, Y.; Lee, S.-T.; Zhong, J.; Kang, Z. Metal-Free Efficient Photocatalyst for Stable Visible Water Splitting via a Two-Electron Pathway. Science 2015, 347, 970-974.

(25) Lau, V. W. H.; Mesch, M. B.; Duppel, V.; Blum, V.; Senker, J.; Lotsch, B. V. Low-Molecular-Weight Carbon Nitrides for Solar Hydrogen Evolution. J. Am. Chem. Soc. 2015, 137, 1064-1072.

(26) Lau, V. W.; Moudrakovski, I.; Botari, T.; Weinberger, S.; Mesch, M. B.; Duppel, V.; Senker, J.; Blum, V.; Lotsch, B. V. Rational Design of Carbon Nitride Photocatalysts by Identification of Cyanamide Defects as Catalytically Relevant Sites. Nat. Commun. 2016, 7, 12165.

(27) Che, W.; Cheng, W.; Yao, T.; Tang, F.; Liu, W.; Su, H.; Huang, Y.; Liu, Q.; Liu, J.; Hu, F.; et al. Fast Photoelectron Transfer in $\left(\mathrm{C}_{\text {ring }}\right)-\mathrm{C}_{3} \mathrm{~N}_{4}$ plane Heterostructural Nanosheets for Overall Water Splitting. J. Am. Chem. Soc. 2017, 139, 3021-3026.

(28) Zhang, G.; Savateev, A.; Zhao, Y.; Li, L.; Antonietti, M. Advancing the $\mathrm{n} \rightarrow \Pi^{*}$ Electron Transition of Carbon Nitride Nanotubes for $\mathrm{H}_{2}$ Photosynthesis. J. Mater. Chem. A 2017, 5, 1272312728.

(29) Zhang, G.; Li, G.; Lan, Z.-A.; Lin, L.; Savateev, A.; Heil, T.; Zafeiratos, S.; Wang, X.; Antonietti, M. Optimizing Optical Absorption, Exciton Dissociation, and Charge Transfer of a Polymeric Carbon Nitride with Ultrahigh Solar Hydrogen Production Activity. Angew. Chem., Int. Ed. 2017, 56, 13445-13449.

(30) Fu, J.; Tian, Y.; Chang, B.; Xi, F.; Dong, X. BiOBr-Carbon Nitride Heterojunctions: Synthesis, Enhanced Activity and Photocatalytic Mechanism. J. Mater. Chem. 2012, 22, 21159-21166.

(31) Zhang, J.; Zhang, M.; Sun, R. Q.; Wang, X. A Facile Band Alignment of Polymeric Carbon Nitride Semiconductors to Construct Isotype Heterojunctions. Angew. Chem., Int. Ed. 2012, 51, 1014510149.

(32) Ou, H.; Chen, X.; Lin, L.; Fang, Y.; Wang, X. Biomimetic Donor-Acceptor Motifs in Conjugated Polymers for Promoting Exciton Splitting And Charge Separation. Angew. Chem., Int. Ed. 2018, 57, 8729-8733.

(33) Zhang, J.; Zhang, G.; Chen, X.; Lin, S.; Möhlmann, L.; Dołęga, G.; Lipner, G.; Antonietti, M.; Blechert, S.; Wang, X. Co-Monomer Control of Carbon Nitride Semiconductors to Optimize Hydrogen Evolution With Visible Light. Angew. Chem., Int. Ed. 2012, 51, 31833187.

(34) Zhang, G.; Wang, X. A Facile Synthesis of Covalent Carbon Nitride Photocatalysts by Co-Polymerization of Urea and Phenylurea for Hydrogen Evolution. J. Catal. 2013, 307, 246-253.

(35) Zhang, J.; Sun, J.; Maeda, K.; Domen, K.; Liu, P.; Antonietti, M.; Fu, X.; Wang, X. Sulfur-Mediated Synthesis of Carbon Nitride: Band-Gap Engineering and Improved Functions for Photocatalysis. Energy Environ. Sci. 2011, 4, 675-679.

(36) Jiang, L.; Yuan, X.; Pan, Y.; Liang, J.; Zeng, G.; Wu, Z.; Wang, $\mathrm{H}$. Doping of graphitic carbon nitride for photocatalysis: A reveiw. Appl. Catal., B 2017, 217, 388-406.

(37) Wang, Y.; Di, Y.; Antonietti, M.; Li, H.; Chen, X.; Wang, X. Excellent Visible-Light Photocatalysis of Fluorinated Polymeric Carbon Nitride Solids. Chem. Mater. 2010, 22, 5119-5121.

(38) Hong, J.; Xia, X.; Wang, Y.; Xu, R. Mesoporous Carbon Nitride with in situ Sulfur Doping for Enhanced Photocatalytic Hydrogen Evolution From Water Under Visible Light. J. Mater. Chem. 2012, 22, $15006-15012$.

(39) Chen, X.; Jun, Y.-S.; Takanabe, K.; Maeda, K.; Domen, K.; Fu, X.; Antonietti, M.; Wang, X. Ordered Mesoporous SBA-15 Type Graphitic Carbon Nitride: A Semiconductor Host Structure for Photocatalytic Hydrogen Evolution with Visible Light. Chem. Mater. 2009, 21, 4093-4095.

(40) Sun, J.; Zhang, J.; Zhang, M.; Antonietti, M.; Fu, X.; Wang, X. Bioinspired Hollow Semiconductor Nanospheres as Photosynthetic Nanoparticles. Nat. Commun. 2012, 3, 1139.

(41) Lin, Z.; Wang, X. Nanostructure Engineering and Doping of Conjugated Carbon Nitride Semiconductors for Hydrogen Photosynthesis. Angew. Chem., Int. Ed. 2013, 52, 1735-1738. 
(42) Sprick, R. S.; Jiang, J. X.; Bonillo, B.; Ren, S.; Ratvijitvech, T.; Guiglion, P.; Zwijnenburg, M. A.; Adams, D. J.; Cooper, A. I. Tunable organic photocatalysts for visible-light-driven hydrogen evolution. J. Am. Chem. Soc. 2015, 137, 3265-3270.

(43) Sprick, R. S.; Bonillo, B.; Sachs, M.; Clowes, R.; Durrant, J. R.; Adams, D. J.; Cooper, A. I. Extended Conjugated Microporous Polymers for Photocatalytic Hydrogen Evolution From Water. Chem. Commun. 2016, 52, 10008-10011.

(44) Li, L.; Lo, W. Y.; Cai, Z.; Zhang, N.; Yu, L. Donor-Acceptor Porous Conjugated Polymers for Photocatalytic Hydrogen Production: The Importance of Acceptor Comonomer. Macromolecules 2016, 49, 6903-6909.

(45) Wang, L.; Wan, Y.; Ding, Y.; Niu, Y.; Xiong, Y.; Wu, X.; Xu, H. Photocatalytic Oxygen Evolution from Low-Bandgap Conjugated Microporous Polymer Nanosheets: A Combined First-Principles Calculation and Experimental Study. Nanoscale 2017, 9, 4090-4096.

(46) Li, L.; Cai, Z. Structure control and photocatalytic performance of porous conjugated polymers based on perylene diimide. Polym. Chem. 2016, 7, 4937-4943.

(47) Yang, C.; Ma, B. C.; Zhang, L.; Lin, S.; Ghasimi, S.; Landfester, K.; Zhang, K. A. I.; Wang, X. Molecular Engineering of Conjugated Polybenzothiadiazoles for Enhanced Hydrogen production by Photosynthesis. Angew. Chem., Int. Ed. 2016, 55, 9202-9206.

(48) Li, L.; Cai, Z.; Wu, Q.; Lo, W. Y.; Zhang, N.; Chen, L. X.; Yu, L. Rational Design of Porous Conjugated Polymers and Roles of Residual Palladium for Photocatalytic Hydrogen Production. J. Am. Chem. Soc. 2016, 138, 7681-7686.

(49) Woods, D. J.; Sprick, R. S.; Smith, C. L.; Cowan, A. J.; Cooper, A. I. A Solution-Processable Polymer Photocatalyst for Hydrogen Evolution From Water. Adv. Energy Mater. 2017, 7, 1700479.

(50) Zong, X.; Miao, X.; Hua, S.; An, L.; Gao, X.; Jiang, W.; Qu, D.; Zhou, Z.; Liu, X.; Sun, Z. Structure Defects Assisted Photocatalytic $\mathrm{H}_{2}$ Production for Polythiophene Nanofibers. Appl. Catal., B 2017, 211, 98-105.

(51) Angewandte Chemie, International Edition. 2016, 55, $1792-1796$.

(52) Sprick, R. S.; Bonillo, B.; Clowes, R.; Guiglion, P.; Brownbill, N. J.; Slater, B. J.; Blanc, F.; Zwijnenburg, M. A.; Adams, D. J.; Cooper, A. I. Visible-Light Driven Hydrogen Evolution Using Planarized Conjugated Polymer Photocatalysts. Angew. Chem., Int. Ed. 2016, 55, $1792-1796$

(53) Sprick, R. S.; Aitchison, C. M.; Berardo, E.; Turcani, L.; Wilbraham, L.; Alston, B. M.; Jelfs, K. E.; Zwijnenburg, M. A.; Cooper, A. I. Maximising the Hydrogen Evolution Activity in Organic Photocatalysts by Co-Polymerisation. J. Mater. Chem. A 2018, 6, 11994-12003.

(54) Bi, J.; Fang, W.; Li, L.; Wang, J.; Liang, S.; He, Y.; Liu, M.; Wu, L. Covalent Triazine-Based Frameworks as Visible Light Photocatalysts for the Splitting of Water. Macromol. Rapid Commun. 2015, 36, 1799-1805.

(55) Schwinghammer, K.; Hug, S.; Mesch, M. B.; Senker, J.; Lotsch, B. V. Phenyl-triazine oligomers for light-driven hydrogen evolution. Energy Environ. Sci. 2015, 8, 3345-3353.

(56) Kuecken, S.; Acharjya, A.; Zhi, L.; Schwarze, M.; Schomäcker, R.; Thomas, A. Fast Tuning of Covalent Triazine Frameworks for Photocatalytic Hydrogen Evolution. Chem. Commun. 2017, 53, 58545857.

(57) Meier, C. B.; Sprick, R. S.; Monti, A.; Guiglion, P.; Lee, J.-S. M.; Zwijnenburg, M. A.; Cooper, A. I. Structure-Property Relationships for Covalent Triazine-Based Frameworks: The Effect of Spacer Length on Photocatalytic Hydrogen Evolution From Water. Polymer 2017, 126, 283-290.

(58) Zhang, Z.; Long, J.; Yang, L.; Chen, W.; Dai, W.; Fu, X.; Wang, $\mathrm{X}$. Organic Semiconductor for Artificial Photosynthesis: Water Splitting into Hydrogen by a Bioinspired $\mathrm{C}_{3} \mathrm{~N}_{3} \mathrm{~S}_{3}$ Polymer under Visible Light Irradiation. Chem. Sci. 2011, 2, 1826-1830.

(59) Chu, S.; Wang, Y.; Guo, Y.; Zhou, P.; Yu, H.; Luo, L.; Kong, F.; Zou, Z. Facile Green Synthesis of Crystalline Polyimide Photocatalyst for Hydrogen Generation from Water. J. Mater. Chem. 2012, 22, $15519-15521$.

(60) Vyas, V. S.; Haase, F.; Stegbauer, L.; Savasci, G.; Podjaski, F.; Ochsenfeld, C.; Lotsch, B. V. A Tunable Azine Covalent Organic Framework Platform for Visible Light-Induced Hydrogen Generation. Nat. Commun. 2015, 6, 8508.

(61) Haase, F.; Banerjee, T.; Savasci, G.; Ochsenfeld, C.; Lotsch, B. V. Structure-Property-Activity Relationships in a Pyridine Containing Azine-Linked Covalent Organic Framework for Photocatalytic Hydrogen Evolution. Faraday Discuss. 2017, 201, 247-264.

(62) Stegbauer, L.; Schwinghammer, K.; Lotsch, B. V. A HydrazoneBased Covalent Organic Framework for Photocatalytic Hydrogen Production. Chem. Sci. 2014, 5, 2789-2793.

(63) Wang, L.; Fernández-Terán, R.; Zhang, L.; Fernandes, D. L. A.; Tian, L.; Chen, H.; Tian, H. Organic Polymer Dots as Photocatalysts for Visible Light-Driven Hydrogen Generation. Angew. Chem., Int. Ed. 2016, 55, 12306-12310.

(64) Yanagida, S.; Ogata, T.; Kuwana, Y.; Wada, Y.; Murakoshi, K.; Ishida, A.; Takamuku, S.; Kusaba, M.; Nakashima, N. Synthesis of $2,^{\prime}: 5^{\prime}, 2^{\prime \prime}$-Terpyridine and $2,2^{\prime}: 5^{\prime}, 2^{\prime \prime}: 5^{\prime \prime}, 2^{\prime \prime \prime}$-Quaterpyridine and their Photocatalysis of the Reduction of Water. J. Chem. Soc., Perkin Trans. 2 1996, 1, 1963-1969.

(65) Matsuoka, S.; Kohzuki, T.; Nakamura, A.; Pac, C.; Yanagida, S. Efficient visible-light-driven photocatalysis. Poly(pyridine-2,5-diyl)catalysed hydrogen photoevolution and Photoreduction of Carbonyl Compounds. J. Chem. Soc., Chem. Commun. 1991, 580-581.

(66) Yamamoto, T.; Yoneda, Y.; Maruyama, T. Ruthenium And Nickel Complexes of a $\pi$-Conjugated Electrically Conducting Polymer Chelate Ligand, Poly (2,2'-bipyridine-5,5'-diyl), and their Chemical and Catalytic Reactivity. J. Chem. Soc., Chem. Commun. 1992, 0, $1652-1654$

(67) Guiglion, P.; Butchosa, C.; Zwijnenburg, M. A. Polymeric Watersplitting Photocatalysts; a Computational Perspective on the Water Oxidation Conundrum. J. Mater. Chem. A 2014, 2, 1199612004.

(68) Guiglion, P.; Butchosa, C.; Zwijnenburg, M. A. Polymer Photocatalysts for Water Splitting: Insights from Computational Modeling. Macromol. Chem. Phys. 2016, 217, 344-353.

(69) Schwarz, C.; Bässler, H.; Bauer, I.; Koenen, J.-M.; Preis, E.; Scherf, U.; Köhler, A. Does Conjugation Help Exciton Dissociation? A Study on Poly ( $p$-phenylene)s in Planar Heterojunctions with $\mathrm{C}_{60}$ or TNF. Adv. Mater. 2012, 24, 922-925.

(70) Sprick, R. S.; Hoyos, M.; Wrackmeyer, M. S.; Sheridan Parry, A. V.; Grace, I. M.; Lambert, C.; Navarro, O.; Turner, M. L. Extended Conjugation in Poly(triarylamine)s: Synthesis, Structure and Impact on Field-Effect Mobility. J. Mater. Chem. C 2014, 2, 6520-6528.

(71) Mohamadi, F.; Richards, N. G. J.; Guida, W. C.; Liskamp, R.; Lipton, M.; Caufield, C.; Chang, G.; Hendrickson, T.; Still, W. C. Macromodel - An Integrated Software System for Modeling Organic and Bioorganic Molecules Using Molecular Mechanics. J. Comput. Chem. 1990, 11, 440-467.

(72) Jorgensen, W. L.; Tirado-Rives, J. The OPLS [Optimized Potentials for Liquid Simulations] Potential Functions for Proteins, Energy Minimizations for Crystals of Cyclic Peptides and Crambin. J. Am. Chem. Soc. 1988, 110, 1657-1666.

(73) Lee, C.; Yang, W.; Parr, R. G. Development of the Colle-salvetti Correlation-Energy Formula into a Functional of the Electron Density. Phys. Rev. B: Condens. Matter Mater. Phys. 1988, 37, 785789.

(74) Becke, A. D. A New Mixing of Hartree-Fock and Local Density-Functional Theories. J. Chem. Phys. 1993, 98, 1372-1377.

(75) Schäfer, A.; Horn, H.; Ahlrichs, R. Fully Optimized Contracted Gaussian Basis Sets for Atoms Li to Kr. J. Chem. Phys. 1992, 97, 2571-2577.

(76) Ahlrichs, R.; Bär, M.; Häser, M.; Horn, H.; Kölmel, C. Electronic Structure Calculations on Workstation Computers: The Program System Turbomole. Chem. Phys. Lett. 1989, 162, 165-169.

(77) van Wüllen, C. Shared-Memory Parallelization of the TURBOMOLE Programs AOFORCE, ESCF, and EGRAD: How to 
Quickly Parallelize Legacy Code. J. Comput. Chem. 2011, 32, 11951201.

(78) Furche, F.; Ahlrichs, R. Erratum: "Time-Dependent Density Functional Methods for Excited State Properties" [J. Chem. Phys. 117, 7433 (2002)]. J. Chem. Phys. 2004, 121, 12772-12773.

(79) Guiglion, P.; Monti, A.; Zwijnenburg, M. A. Validating a Density Functional Theory Approach for Predicting the Redox Potentials Associated with Charge Carriers and Excitons in Polymeric Photocatalysts. J. Phys. Chem. C 2017, 121, 1498-1506.

(80) Klamt, A.; Schüürmann, G. COSMO: A New Approach to Dielectric Screening in Solvents with Explicit Expressions for the Screening Energy and its Gradient. J. Chem. Soc., Perkin Trans. 2 1993, 5, 799-805.

(81) Barone, V.; Cossi, M.; Tomasi, J. Geometry Optimization of Molecular Structures in Solution by the Polarizable Continuum Model. J. Comput. Chem. 1998, 19, 404-417.

(82) Furche, F.; Ahlrichs, R.; Hättig, C.; Klopper, W.; Sierka, M.; Weigend, F. Turbomole. Wiley Interdiscip. Rev. Comput. Mol. Sci. 2014, 4, 91-100.

(83) Ahlrichs, R.; Armbruster, M. K.; Bachorz, R. A.; Bär, M.; Baron, H.-P.; Bauernschmitt, R.; Bischoff, F. A.; Böcker, S.; Burow, A. M.; Crawford, N.; et al. TURBOMOLE, version V7.01 2010; Turbomole GmbH: Karlsruhe, Germany, 2015.

(84) Hirata, S.; Head-Gordon, M. Time-Dependent Density Functional Theory within the Tamm-Dancoff Approximation. Chem. Phys. Lett. 1999, 314, 291-299.

(85) Peach, M. J. G.; Tozer, D. J. Overcoming Low Orbital Overlap and Triplet Instability Problems in TDDFT. J. Phys. Chem. A 2012, 116, 9783-9789.

(86) Marenich, A. V.; Cramer, C. J.; Truhlar, D. G. Universal Solvation Model Based on Solute Electron Density and on a Continuum Model of the Solvent Defined by the Bulk Dielectric Constant and Atomic Surface Tensions. J. Phys. Chem. B 2009, 113, 6378-6396.

(87) Frisch, M. J.; Trucks, G. W.; Schlegel, H. B.; Scuseria, G. E.; Robb, M. A.; Cheeseman, J. R.; Scalmani, G.; Barone, V.; Mennucci, B.; Petersson, G. A.; Nakatsuji, H.; Caricato, M.; Li, X.; Hratchian, H. P.; Izmaylov, A. F.; Bloino, J.; Zheng, G.; Sonnenberg, J. L.; Hada, M.; Ehara, M.; Toyota, K.; Fukuda, R.; Hasegawa, J.; Ishida, M.; Nakajima, T.; Honda, Y.; Kitao, O.; Nakai, H.; Vreven, T.; Montgomery, J. A., Jr.; Peralta, J. E.; Ogliaro, F.; Bearpark, M.; Heyd, J. J.; Brothers, E.; Kudin, K. N.; Staroverov, V. N.; Kobayashi, R.; Normand, J.; Raghavachari, K.; Rendell, A.; Burant, J. C.; Iyengar, S. S.; Tomasi, J.; Cossi, M.; Rega, N.; Millam, J. M.; Klene, M.; Knox, J. E.; Cross, J. B.; Bakken, V.; Adamo, C.; Jaramillo, J.; Gomperts, R.; Stratmann, R. E.; Yazyev, O.; Austin, A. J.; Cammi, R.; Pomelli, C.; Ochterski, J. W.; Martin, R. L.; Morokuma, K.; Zakrzewski, V. G.; Voth, G. A.; Salvador, P.; Dannenberg, J. J.; Dapprich, S.; Daniels, A. D.; Farkas, O.; Foresman, J. B.; Ortiz, J. V.; Cioslowski, J.; Fox, D. J. Gaussian 09, revision C.01; Gaussian, Inc.: Wallingford, CT, 2009.

(88) Sprick, R. S.; Hoyos, M.; Navarro, O.; Turner, M. L. Synthesis of poly(triarylamine)s by $\mathrm{C}-\mathrm{N}$ Coupling Catalyzed by ( $\mathrm{N}$-Heterocyclic Carbene)-Palladium Complexes. React. Funct. Polym. 2012, 72, 337-340.

(89) Sprick, R. S.; Hoyos, M.; Morrison, J. J.; Grace, I. M.; Lambert, C.; Navarro, O.; Turner, M. L. Triarylamine Polymers of Bridged Phenylenes by ( $\mathrm{N}$-Heterocyclic Carbene)-Palladium Catalysed $\mathrm{C}-\mathrm{N}$ Coupling. J. Mater. Chem. C 2013, 1, 3327-3336.

(90) Wilbraham, L.; Berardo, E.; Turcani, L.; Jelfs, K. E.; Zwijnenburg, M. A. A High-Throughput Screening Approach for the Optoelectronic Properties Of Conjugated Polymers. J. Chem. Inf. Model. 2018, DOI: $10.1021 /$ acs.jcim. 8 b00256

(91) Soares, J. A. N. T. Introduction to Optical Characterization of Materials. In Practical Materials Characterization; Springer New York: New York, NY, 2014; pp 43-92.

(92) Yan, H.; Huang, Y. Polymer Composites of Carbon Nitride and Poly(3-hexylthiophene) to Achieve Enhanced Hydrogen Production from Water under Visible Light. Chem. Commun. 2011, 47, 41684170 .
(93) Bi, S.; Lan, Z.-A.; Paasch, S.; Zhang, W.; He, Y.; Zhang, C.; Liu, F.; Wu, D.; Zhuang, X.; Brunner, E.; et al. Subst substantial CyanoSubstituted fully $\mathrm{sp}^{2}$-Carbon-Linked Framework: Metal-Free Approach and Visible-Light-Driven Hydrogen evolution. Adv. Funct. Mater. 2017, 27, 1703146. 